\title{
A historiografia literária brasileira: experiências contemporâneas
}

\author{
Brazilian literary historiography: contemporary experiences
}

\author{
Carlos Alexandre Baumgarten \\ Pontifícia Universidade Católica do Rio Grande do Sul - Porto Alegre - Rio Grande do Sul - Brasil
}

-

\begin{abstract}
Resumo: O trabalho, "A historiografia literária brasileira: experiências contemporâneas", realiza o estudo da historiografia literária brasileira contemporânea em algumas de suas manifestações, como é o caso de Uma história do romance de 30 (2006), de Luís Bueno, e de Como e por que ler o romance brasileiro (2004), de Marisa Lajolo. Além disso, analisa duas antologias, que igualmente revelam intenção historiográfica: Antologia da poesia afro-brasileira: 150 anos de consciência negra no Brasil (2011), organizada por Zilá Bernd, e Antologia comentada da poesia brasileira do século XXI (2006), de Manuel da Costa Pinto. O exame desse corpus, desenvolvido a partir dos pressupostos estabelecidos pela Teoria da História da Literatura, aponta para a necessidade do desenvolvimento de estudo sobre material significativo para a compreensão do processo de escrita da história da literatura brasileira hoje.
\end{abstract}

Palavras-chave: Historiografia literária; Antologias; Subjetividade

\begin{abstract}
Brazilian literary historiography: contemporary experiences" is an approach on some Brazilian literary historiographic works, such as Uma história do romance de 30 (2006) ["A history of 30's novel"], by Luís Bueno, and Como e por que ler o romance brasileiro (2004) ["How and why to read the Brazilian novel"], by Marisa Lajolo. Moreover, two antologies are analyzed, which also revealed historiographic purposes: Antologia da poesia afro-brasileira: 150 anos de consciência negra no Brasil (2011) ["Anthology of Afro-Brazilian poetry: 150 years of black identity in Brazil"], edited by Zilá Bernd, and Antologia comentada da poesia brasileira do século XXI (2006) ["Commented anthology of 21st Century Brazilian poetry"], by Manuel da Costa Pinto. The study of this corpus, drawing on the concepts of the Theory of History of Literature, addresses that further studies are needed to understand the Brazilian literary history writing process nowadays.
\end{abstract}

Keywords: Literary historiography; Anthologies; Subjectivity

A História da Literatura desenvolveu-se e afirmou-se no curso do século XIX, a partir da influência do Positivismo que via na História a ciência capaz de resgatar o passado, recuperando os eventos tal como haviam verdadeiramente ocorrido. Tal crença não só proporcionou um rápido crescimento da ciência histórica, como também determinou que sua influência se disseminasse por todos os campos do saber oitocentista. Esse prestígio alcançado pela História transferiu-se para a História da Literatura que, em boa parte do século XIX, estabeleceu-se como a principal disciplina e referência do campo dos estudos literários. A centralidade então alcançada pela História da Literatura deveu-se, também, à coincidência de sua ascensão com a consolidação dos estados nacionais que, tanto na América quanto na Europa, necessitavam de um discurso que os legitimasse e confirmasse em sua singularidade. Nesse contexto, a História da Literatura assume relevante papel social, pois cabia a ela não apenas a recuperação do acervo literário das comunidades nacionais, como a elaboração de um discurso que, construído a partir desse acervo, comprovasse a existência de uma unidade cultural no âmbito dessas mesmas comunidades.

Contudo, se a História e a própria História da Literatura adquiriram prestígio graças aos postulados positivistas, foi devido a esses mesmos postulados que entraram em declínio e viram sua metodologia no trato da matéria histórica e literária ser posta em questão. No campo da História, essa situação configurou uma espécie de "crise", já que o questionamento da atitude 
positivista tornou evidente que a crença na objetividade dos dados históricos era traída pela sua seleção e ordenação, inescapavelmente afetadas pela subjetividade do historiador ao estabelecer suas hipóteses.

A História da Literatura, por seu turno, a partir de uma pretensa objetividade a ser alcançada, organizava o acervo literário segundo conceitos como os de período e grupos, desconsiderando a natureza estética das obras literárias, ficando restrita ao que poderíamos chamar de uma estética da produção. Essa direção assumida pela História da Literatura foi determinante para sua crescente marginalidade no âmbito dos estudos literários, condição a que ficou relegada pelo menos até meados da segunda metade do século XX. Nesse sentido, a História da Literatura, havendo surgido no ambiente intelectual que produziu e promoveu o historicismo, viu-se igualmente atingida pela chamada "crise da história", iniciada ainda no fim do século XIX e aprofundada no início do século XX.

Com um novo quadro intelectual de inclinação antihistoricista estabelecido, os estudos literários passaram a sofrer a influência de correntes cuja característica principal era a contestação dos métodos da História da Literatura. Situam-se, nesse âmbito, as propostas formuladas notadamente pela Estilística e pela Nova Crítica, e em menor extensão por aquelas contidas no pensamento dos formalistas russos, todas elas adeptas de uma abordagem imanente das obras literárias. Tal quadro abriu espaço para a ascensão da Teoria da Literatura que, gradativamente, vai assumindo um protagonismo acadêmico antes desfrutado pela História da Literatura. É interessante ressaltar que, no Brasil, são desse período duas publicações que, a despeito de sua natureza e orientação diversa, apresentam títulos que revelam a tentativa de se desvincularem da historiografia literária tradicional: de um lado, A formação da literatura brasileira - momentos decisivos, de Antonio Candido; de outro, A literatura no Brasil, organizada por Afrânio Coutinho. Em ambos os casos, o que se tem é a escrita de uma história da literatura brasileira, embora com abrangência e orientação distintas.

Somente em meados da segunda metade do século passado, é que a história da literatura, em virtude da emergência de novas orientações teóricas surgidas no campo dos estudos históricos, volta a ocupar posição relevante nos debates que então se processam. Tais debates, vinculados especialmente à reflexão sobre as relações entre o discurso histórico e o discurso literário, têm origem nas sugestões primeiras constantes das propostas dos historiadores franceses da Escola dos Anais. A estas se seguem, no final da década de 60, as formulações de Hans Robert Jauss, com o seu A história de literatura como provocação à teoria literária, texto inaugurador da Estética da Recepção. Nele, o teórico alemão busca superar a distância existente entre o conhecimento histórico e o conhecimento estético das obras literárias, que se harmonizariam pela consideração de uma instância que é a da recepção a que as obras são submetidas ao longo de sua trajetória. Cabe registrar, ainda, que, no curso dos anos 80 , a reflexão envolvendo as relações entre História e Literatura foi enriquecida pelas contribuições do movimento que ficou conhecido como Nova História.

Todas essas tentativas, aqui sumariamente enunciadas, ao pensarem a relação entre literatura e história, e ao reafirmarem a importância da História da Literatura, esbarram em diversos problemas estruturais, como os relacionados aos conceitos que o historiador tem de literatura, de história, de sociedade, de ideologia. Além disso, devem elas enfrentar a questão do momento histórico em que determinada historia literária é produzida, pois forças sociais, culturais e ideológicas interferem na visão que uma determinada sociedade tem em relação ao seu passado, sua história e sua identidade. Na busca por soluções para esses impasses, vários têm sido os teóricos a proporem alternativas, como as apontadas por Siegfried Schmidt, David Perkins, Niklas Luhmann, Harro Müller, Hans Ulrich Gumbrecht, Franco Moreti, entre tantos outros.

Enfim, especialmente a partir dos anos 70 do século passado, observa-se o surgimento e a afirmação de um forte movimento cujo objetivo é repensar a escrita da história da literatura, segundo novos parâmetros, sejam aqueles apontados por correntes do pensamento historiográfico vinculado aos caminhos abertos pela Teoria da História da Literatura e pela Teoria da Literatura, sejam aqueles concebidos no âmbito da reflexão histórica produzida nas décadas finais do século XX. Tal movimento não apenas recoloca a História da Literatura como objeto de reflexão constante no âmbito da academia, como proporciona o aparecimento de uma historiografia literária que, no seu conjunto, abdica do perfil totalizador apresentado pelas histórias da literatura de feitio tradicional, determinando o surgimento de novas formas no historiar a literatura.

No Brasil, a repercussão alcançada pelos novos caminhos apontados pelo pensamento histórico e, particularmente, por aqueles abertos pela Teoria da História da Literatura, ganha relevância, especialmente a partir dos anos 80 do século passado, através da divulgação dos trabalhos realizados pelos integrantes do grupo inicialmente vinculado às teses estabelecidas pela estética da recepção e também por aqueles desenvolvidos por historiadores alinhados com as propostas renovadoras surgidas no âmbito da ciência histórica. Nesse sentido, surgem publicações como A literatura e o leitor (Textos de estética da recepção), 1979, Teoria da literatura em suas fontes (1983), ambas organizadas por Luiz Costa 
Lima, Estética da recepção e história da literatura (1989), de Regina Zilberman, História da literatura: ensaios (1994), de Letícia Malard e outros, Histórias de literatura: as novas teorias alemãs (1996), organização de Heidrun Krieger Olinto, que, entre muitos outras, atestam a preocupação com o repensar a escrita e o lugar da História da Literatura no plano dos estudos literários.

Essa preocupação tem como uma de suas consequências mais significativas a revisão da historiografia literária brasileira que, além de ser estudada minuciosamente, tem seus textos fundamentais resgatados e postos em circulação. Nesse sentido, é importante registrar trabalhos como os desenvolvidos por Regina Zilberman e Maria Eunice Moreira, com a publicação de O berço do cânone (1998), reunião de textos fundadores da história da literatura brasileira, e por Roberto Acízelo de Souza que, entre outros tantos trabalhos, recolocou em circulação História da literatura brasileira e outros ensaios (2002), de Joaquim Norberto de Sousa Silva, e Historiografia da literatura brasileira: textos inaugurais (2007), de Joaquim Caetano Fernandes Pinheiro.

A ampla discussão sobre a História da Literatura é também responsável por um conjunto de ações que comprovam sua repercussão no meio acadêmico brasileiro: de um lado, a realização de continuados seminários e congressos, nacionais e internacionais, que se ocupam da reflexão sobre a História da Literatura; de outro, a constituição, no âmbito da Anpoll, de um Grupo de Trabalho voltado para o seu estudo. Além disso, assiste-se, igualmente, ao surgimento de programas de pós-graduação stricto sensu que elegem a História da Literatura como uma de suas áreas de concentração.

Nesse cenário construído pelos caminhos assumidos pela ciência histórica e pela própria Teoria da História da Literatura, abrem-se, igualmente, novas possibilidades para a escrita da história da literatura brasileira que, via de regra, tem abandonado as antigas pretensões de natureza totalizadora, optando por recortes de ordem pontual, como é o caso de Uma história do romance de 30, de Luís Bueno. $\mathrm{O}$ autor, ao eleger uma categoria de gênero (o romance) e um período de tempo específico (década de 30 ), realiza uma ampla pesquisa da produção contida no referido período, promovendo a revisão de importante capítulo da história da literatura brasileira e do cânone estabelecido.

Luiz Bueno organiza a obra em três partes distintas: "Dois problemas gerais", "Três tempos de 30" e "Quatro autores". Num primeiro momento, focaliza os problemas de ordem teórica referentes ao chamado romance de 30 para, a partir daí, definir o lugar por ele ocupado na série romanesca brasileira. A segunda etapa do trabalho ocupase de um número significativo de obras identificadas pelo Autor como importantes para a compreensão do romance brasileiro produzido no âmbito da década investigada, aspecto que revela o critério utilizado por Bueno no sentido de realizar uma leitura extensiva - em princípio, qualquer romance publicado entre 1930 e 1939 interessou ao trabalho e, desde que se localizasse um exemplar, foi lido (BUENO, 2006, p. 15). As obras elencadas, a despeito de seu grande número, são analisadas a partir da constatação de que a década foi marcada por um embate entre duas grandes linhas: a do romance social, quantitativamente superior, e a do romance psicológico. No confronto entre uma tendência e outra, abre-se espaço para a afirmação de um tema dominante: o da "configuração do outro", materializada através da ascensão de figuras até então marginalizadas ou mesmo ausentes da ficção brasileira anterior, como é o caso do proletário, do homossexual e da mulher. A última etapa do trabalho, "Quatro autores", contempla a análise de quatro autores cujas obras, segundo o Autor, sintetizam as principais diretrizes assumidas pelo romance produzido na década de 30: Cornélio Penna, Graciliano Ramos, Cyro dos Anjos e Dionélio Machado.

Uma leitura, mesmo que ligeira, da obra de Luís Bueno permite a constatação de alguns aspectos decorrentes do posicionamento assumido pelo historiador: em primeiro lugar, cabe destacar a presença do indefinido "uma" constante do título, a sinalizar que o autor tem plena consciência de que seu trabalho constitui apenas uma das possibilidades de se abordar, no plano de uma perspectiva historiográfica, o romance brasileiro produzido na década de 30 , restando possíveis outros tantos caminhos a serem trilhados pelos historiadores de nossa literatura, pois, como bem apontou David Perkins, recorrendo a Fredric Jameson, todo relato histórico é sempre marcado por um certo grau de partidarismo, intimamente vinculado às escolhas e ao próprio desejo do historiador. Em suma, a subjetividade do historiador, ao conceber e organizar o seu relato, interfere nas opções por ele assumidas e, não raramente, no lugar mais ou menos importante que concede a autores e obras (PERKINS, 1999, p. 4-5).

Um segundo aspecto importante de Uma história do romance de 30 é o vinculado ao período investigado: os romances brasileiros publicados unicamente na década de 30 . A concisão do recorte estabelecido pelo historiador garante o levantamento exaustivo das obras publicadas no período, sendo o responsável pelo resgate de produções praticamente ausentes da historiografia literária brasileira, como é caso de Sob o olhar malicioso dos trópicos, de Barreto Filho, que é cuidadosamente analisado e que tem redimensionada sua posição para a compreensão do conjunto dos romances então produzidos. Além da obra de Barreto Filho, é importante mencionar o exame das obras de outros romancistas, como Lúcia Miguel-Pereira, Lúcio Cardoso, entre outros, até há pouco tempo raramente analisadas e valorizadas pela crítica e historiografia 
literária brasileira. Com tal estratégia, Bueno contribui, também, para a ampliação do cânone literário brasileiro, ao incorporar um conjunto de produções não contemplado pelas histórias da literatura precedentes.

Igualmente significativa é a opção de Luís Bueno por pensar a produção da década de 30 a partir de uma relação que se dá no âmbito do próprio sistema literário brasileiro, aspecto que o faz abandonar a perspectiva comparatista que, normalmente, marca a escrita da história da literatura brasileira. Nesse sentido, as obras são analisadas em sua relação com aquelas que as antecederam ou as sucederam no plano da produção literária do País, num procedimento que aproxima seu trabalho do conceito de autopoiesis, tal como concebido por Maturana no âmbito da Biologia, e utilizado por Gebhard Rusch, ao pensar, na contemporaneidade, a escrita da história da literatura. A consequência de tal escolha, que é um dos aspectos que torna singular seu trabalho, é a consideração do sistema literário brasileiro como um sistema autônomo, capaz de, no curso dos anos 30, revelar maturidade para, a partir de elementos (obras) já existentes em seu interior, gerar novos elementos (obras).

Por último, nessa breve síntese dos aspectos caracterizadores do trabalho de Bueno, cabe ressaltar que, para além de uma grande lista de autores e obras, Uma história do romance de 30 constrói-se, como bem disse seu autor, no enfrentamento dos textos (BUENO, 2006, p. 11), atitude que faz dela, também, um grande exercício de crítica literária, materializado, não apenas nos capítulos iniciais, mas, sobretudo, na última parte dedicada à leitura das obras de Cornélio Penna, Graciliano Ramos, Cyro dos Anjos e Dionélio Machado.

Outra experiência significativa, no âmbito da historiografia literária brasileira contemporânea, é o trabalho realizado por Marisa Lajolo, em "Como e por que ler o romance brasileiro". Publicado no ano de 2004, o volume integra a Coleção "Como e por que ler", da Editora Objetiva e, como os restantes da referida série, tem por objetivo contribuir para a formação de leitores, no caso, de leitores do romance brasileiro. Contudo, bem mais do que isso, a obra acaba por se constituir num exercício de escrita historiográfica que, a partir da recuperação da trajetória de leitura de um leitor específico - a própria autora -, reconstitui o percurso do romance brasileiro, desde seus textos iniciais até obras contemporâneas.

No primeiro capítulo, já se estabelece o tom confessional assumido pelo discurso de Lajolo desde o início do texto, que se abre do seguinte modo: "Quem é que assina este livro que promete discutir o romance brasileiro? Sou eu, Marisa Lajolo, professora titular de literatura na Unicamp. Antes de mais nada, porém, leitora fiel de romances." (LAJOLO, 2004, p. 13). O restante do capítulo é dedicado à recuperação do período de formação da leitora, que apresenta um conjunto de obras, "sem cronologia, na sequência da memória." (LAJOLO, 2004, p. 17). Assim, o leitor fica sabendo da primeira experiência de leitura do romance brasileiro vivida pela autora/ narradora: trata-se de "Inocência", de Taunay. A seguir, sem nenhuma ordem senão aquela ditada pela memória, surgem "As meninas" e "As horas nuas", de Lygia Fagundes Teles, "Zero", de Ignácio de Loyola Brandão, "As alegres memórias de um cadáver", de Roberto Gomes, "A margem imóvel do rio", de Luís Antônio de Assis Brasil, entre muitos outros. O que se observa na leitura desse primeiro capítulo é que Lajolo realiza, em verdade, de um exercício de ego-história, nos termos estabelecidos por Pierre Nora (1989), especialmente pela consideração dos aspectos subjetivos do próprio discurso e pelo fato de o historiador ser, simultaneamente, sujeito e objeto de seu discurso. Assim, ao contrário da impessoalidade (fingida) das histórias da literatura de perfil tradicional, o que se tem é a presença de um narrador que assume, em seu discurso, um tom propositadamente subjetivo, em que os apelos explícitos ao leitor constituem uma marca constante.

O capítulo subsequente, "O romance e a leitura sob suspeita", se encarrega de focalizar o gênero romance em sua história e, particularmente, sua importância na formação de leitores no Brasil do século XIX, especialmente a partir da divulgação de folhetins, de autoria de nacionais e estrangeiros. É também o momento para afirmar a importância social do gênero, notadamente no que diz respeito às repercussões alcançadas por ele na formação dos sujeitos leitores.

É, contudo, a partir do terceiro capítulo, que o trabalho de Lajolo assume contornos de uma história do romance brasileiro, que é vista a partir de recortes que não observam uma ordem cronológica, mas se organizam segundo critérios outros estabelecidos pela autora. Assim, em "Ler e escrever no feminino", título do terceiro capítulo, Lajolo se ocupa com o papel desempenhado pela mulher, seja como personagem, seja como autora, no desenvolvimento do gênero no Brasil. Nesse âmbito, destaca "A moreninha", de Joaquim Manuel de Macedo, pois "será que uma protagonista moreninha, em substituição às tradicionais pálidas e loiras, não falava mais alto ao coração do leitorado brasileiro? É possível que sim, que pele morena e cabelo escuro fossem um bemvindo abrasileiramento da beleza feminina." (LAJOLO, 2004, p.49). Na sequência, é destacada uma série de autoras que, com suas obras, fizeram da mulher não mais apenas consumidoras de romances, mas produtoras, como os casos de Alina Paim, com "A hora próxima" (1950), de Ana Luiza de Azevedo Castro, com "Dona Narcisa de Villar", de Clarice Lispector, com "A hora da estrela", de "Rachel de Queiroz, com "Memorial de Maria Moura", 
todas elas obras que estabelecem rupturas no que diz respeito ao papel e ao lugar ocupado pela mulher, tanto na produção de literatura, quanto na atuação direta no universo social.

Em "O Brasil no mapa do romance", capítulo quarto de seu trabalho, Lajolo focaliza o surgimento do romance urbano brasileiro. Nesse sentido, valendo-se de um critério que é histórico, mas também geográfico, começa pelo Rio de Janeiro, destacando as contribuições de Macedo, de Alencar, de Machado de Assis, de Manuel Antônio de Almeida, de Aluísio Azevedo, de Raul Pompéia, de Lima Barreto, de Júlia Lopes de Almeida, até atingir "Cidade de Deus", de Paulo Lins. São Paulo só vai figurar no "mapa do romance" após as décadas iniciais do século XX, quando entram em cena as produções de Mário e Oswald de Andrade, com "Amar, verbo intransitivo" e "Memórias sentimentais de João Miramar". A partir de então, a prosa urbana se espalharia pelo Brasil, com Cyro dos Anjos e Autran Dourado, em Minas Gerais, com Erico Verissimo, no Rio Grande do Sul, com Milton Hatoun, em Manaus... Esse mapeamento da prosa urbana brasileira é encerrado com o exame de duas obras contemporâneas, também ambientadas em São Paulo: "Eles eram muito cavalos", de Luiz Ruffato, e "Capão pecado", de Ferréz.

Em "O romance viaja pelo Brasil", quinto capítulo, Lajolo se encarrega de reunir obras que "a crítica chama - às vezes com nariz empinado, mau humor e sobrolho franzido - de romance regionalista." (LAJOLO, 2004, p.90). O périplo, aqui, começa com o Alencar, de "Iracema", segue com Taunay, de "Inocência, com Franklin Távora de "O cabeleira", com Euclides da Cunha de "Os sertões", com Graciliano de "Vidas secas", com Jorge Amado de "Gabriela, cravo e canela", para encerrarse com Guimarães Rosa de "Grande sertão veredas" e Ariano Suassuna com o "Romance da pedra do reino".

O penúltimo capítulo - Histórias da história invadem o romance - ocupa-se da apropriação da história por parte do romance brasileiro, ou seja, focaliza o que comumente é identificado como romance histórico. Após breve alusão a "Xangô de Baker Street", de Jô Soares, são comentados "O guarani", de Alencar, o "Rei negro", de Coelho Neto, "A marquesa de Santos", de Paulo Setúbal, "O tempo e o vento", de Erico Verissimo, "Romance sem palavras", de Cony, "Viva o povo brasileiro", de João Ubaldo Ribeiro, e, por fim, "Desmundo", de Ana Miranda.

O trabalho se encerra com - Romances e leitores: queda de braço sempre recomeçada - em que são focalizados dois tópicos específicos: de um lado, o recurso utilizado pelo narrador para alcançar a cumplicidade do leitor, casos de Manuel Antônio de Almeida e de Machado de Assis; de outro, os romance que se fazem a partir do dialogo que estabelecem com outros romances, como é o caso d Silviano Santiago com "Em liberdade", e de Ana Maria Machado, com "A audácia dessa mulher".

A renovação do discurso historiográfico brasileiro manifesta-se, igualmente, através da publicação de uma série de antologias, organizadas a partir de critérios os mais distintos, cujo objetivo e intenção se revelam claramente historiográficos. Esse é o caso, por exemplo, de duas publicações que são objeto, a seguir, de breve exame: Antologia da poesia afro-brasileira: 150 anos de consciência negra no Brasil (2011), organizada por Zilá Bernd, e Antologia comentada da poesia brasileira do século XXI (2006), organizada por Manuel da Costa Pinto.

A Antologia da poesia afro-brasileira: 150 anos de consciência negra no Brasil (2011), de Zilá Bernd, configura-se como uma edição revista e aumentada de publicação originalmente divulgada no ano de 1992. Organizada a partir de um critério de natureza étnica, antologia objetiva o resgate da produção de autores brasileiros afro-descendentes e, por extensão, uma ampliação do cânone literário brasileiro. Tal intenção é evidenciada no prefácio à segunda edição, assinado por Eduardo de Assis Duarte, que afirma:

A presente antologia cumpre, desde sua primeira edição, em 1992, papel de relevo junto a pesquisadores e estudantes de nossas letras interessados em ultrapassar os limites da literatura oficialmente estabelecida nos manuais e currículos escolares. Sua aparição soou como canto de esperança para uma pletora de textos e escritores condenados ao esquecimento. (BERND, 2011, VII)

$\mathrm{Na}$ “Apresentação da edição de 2011”, Zilá Bernd recupera o objetivo que a motivara a lançar a primeira edição da obra: o desejo de promover o resgate da memória social do negro no Brasil através das manifestações poéticas publicadas a partir de 1859. (BERND, 2011, p.20) No mesmo texto, a autora elenca, entre outras justificativas para a reedição ampliada da obra, o objetivo da Lei 10.639/03, que estabelece o estímulo ao ensino da história e da literatura afro-brasileiras na Educação Básica. Além disso, justifica também a opção por "poesia afro-brasileira", ao invés de "literatura negra": de um lado, pelo fato de a primeira expressão remeter apenas à origem étnica da maioria dos autores; de outro, em virtude de "literatura negra" poder remeter à existência de uma essência negra. Na defesa de sua escolha, Zilá Bernd não apenas aponta para a tendência do uso da expressão "afrobrasileira", constante de publicações recentes, como recorre a um conjunto de estudiosos, como Sueli Meira Liebig, Luiza Lobo e Eduardo de Assis Duarte que, em seus escritos, assumem idêntica posição.

A Antologia da poesia afro-brasileira: 150 anos de consciência negra no Brasil contempla vinte e sete autores 
e cento e vinte e seis poemas que, segundo a autora, apresentam duas grandes tendências: a primeira, a do "enraizamento identitário", se ocuparia da recuperação da memória, como forma de unir a comunidade negra em sua luta contra o preconceito ainda hoje existente na sociedade brasileira; a segunda, a "enraizamento dinâmico e relacional", conceito buscado em Michel Maffesoli, buscaria a afirmação da identidade como algo a ser construído no respeito à diversidade e na abertura para a relação com o outro (BERND, 2011, p. 24).

O texto da "Apresentação" traz, ainda, um último subtítulo - "Como a antologia pode ser utilizada" que oferece uma série de sugestões de atividades que podem ser desenvolvidas em sala de aula, evidenciando seu caráter que, para além de historiográfico, é também didático. Assim, sugerem-se o estudo dos símbolos, da menção das figuras históricas e míticas, da enunciação feminina, do vocabulário da senzala, entre outros.

$\mathrm{Na}$ “Apresentação da edição de 1992", constante do volume reeditado, a organizadora apresenta outros critérios que nortearam a escolha dos autores e textos. Tais critérios, para além de seu viés quantitativo, revelam igualmente uma preocupação de ordem estética, como se pode depreender da afirmativa seguinte:

A seleção de textos obedeceu rigorosamente ao critério da representatividade dos autores (autores com no mínimo duas ou três obras publicadas), do grau de literariedade de suas produções e pautou-se por uma classificação estabelecida por mim em Negritude e literatura na América Latina (1987). (BERND, 2011, p. 26)

A organização da antologia observa um critério essencialmente cronológico, uma vez que é ordenada em três grandes períodos: o Pré-Abolicionista, o PósAbolicionista e o Contemporâneo, cada um deles subdividido em vários itens nominados a partir de uma característica identificada na produção de cada autor selecionado. É importante registar que os dois primeiros períodos abarcam apenas trinta e uma páginas, enquanto o último, duzentos e treze. Sendo assim, constam dos primeiros unicamente três autores: Luís Gama, Cruz e Sousa e Lino Guedes. O período contemporâneo conta com os outros vinte e quatro autores constantes da antologia. Este último, por mais extenso, é organizado, em seu início, a partir do tópico "consciência". Assim, os poetas são agrupados em virtude de sua poesia expressar uma "consciência resistente", uma "consciência dilacerada", ou uma "consciência trágica". A seguir, evidenciando uma mudança de critério, apresenta-se a "A poesia afrobrasileira no feminino", quando são destacadas as poetas Conceição Evaristo, Miriam Alves, Leda Maria Martins, Esmeralda Ribeiro, Jussara Santos e Ana Cruz. Por fim, há dois outros grandes blocos, constituído por aqueles autores cuja poesia evidenciaria a presença das duas grandes tendências antes referidas: a do "enraizamento identitário", e a do "enraizamento dinâmico e relacional".

Os poemas de cada autor são precedidos por uma breve "Biografia", por sua "Bibliografia" e por um sucinto comentário crítico, a cargo da organizadora Zilá Bernd, ou dos coorganizadores, Emilene Corrêa Souza e Plínio Carlos Corrêa Souza Jr. Cada poeta tem, no mínimo, um texto selecionado, caso de Abdias do Nascimento, ou, no máximo, oito textos, caso de Cuti, pseudônimo de Luiz Silva. Os comentários críticos não estão, via de regra, diretamente vinculados aos textos selecionados, mas assumem um caráter geral que busca caracterizar o conjunto da produção poética de cada autor. Veja-se, a título de exemplo, parte da apreciação crítica da obra de Solano Trindade:

Solano Trindade vincula-se à vertente de poetas da Negritude antilhana, como Nicolás Guillén e Aimé Césaire, caracterizada pelo engajamento ao marxismo e por um forte sentimento de pertença ao solo americano. O eu-lírico emerge no poema para evocar com orgulho suas raízes africanas e afirmar sua vinculação à América. (BERND, 2011, p. 62)

Concebida da forma como foi apresentada, a Antologia da poesia afro-brasileira: 150 anos de consciência negra no Brasil, de Zilá Bernd, cumpre integralmente seus objetivos: de um lado, caracteriza-se como uma história da poesia brasileira de autoria de afro-descendentes, sem, contudo, assumir um perfil de natureza totalizadora, já que estabelece critérios de seleção, quantitativos e qualitativos, que estão claramente formulados em sua introdução; de outro, promove o resgate de um conjunto de autores que, em sua quase totalidade, estão ausentes das histórias da literatura brasileira. Com tal procedimento, a autora não apenas disponibiliza aos pesquisadores material significativo para a compreensão do sistema literário nacional, como também promove um alargamento do cânone literário brasileiro, intenção que compartilha com aqueles trabalhos que vêm sendo realizados no âmbito dos discursos situados à margem da historiografia literária brasileira tradicional.

O desejo de mapear e, em certa medida, historiar a literatura brasileira, particularmente através da organização de antologias, tem seu exemplo mais radical em Antologia comentada da poesia brasileira do século XXI (2006), de Manuel da Costa Pinto. Divulgado pela Publifolha de São Paulo, o trabalho de Manuel da Costa Pinto reúne setenta poetas em atividade nos primeiros anos do atual século. Na "Apresentação", o autor aponta o desafio que teve de enfrentar pelo fato de reunir, num mesmo volume, autores já consagrados, com vários livros publicados e extensa fortuna crítica, ao lado de poetas que 
editaram apenas uma ou duas coletâneas praticamente desconhecidas do público e com recepção incipiente nos jornais e nas revistas especializadas. (PINTO, 2006, p.9). Nesse sentido, a antologia reúne poetas com extensa produção como Haroldo de Campos, Augusto de Campos, Mário Chamie, Francisco Alvim, e poetas com produção que data dos anos 90 em diante, com Sérgio Alcides e Manuel Ricardo de Lima, entre outros.

O exame do trabalho de Manuel da Costa Pinto revela que o mesmo, a exemplo dos anteriores, reveste-se de uma intenção historiográfica, porquanto traça um amplo painel da produção poética brasileira do século XXI, reunindo textos de setenta poetas, número que pareceu suficiente para apresentar um quadro amplo da produção contemporânea (PINTO, 2006, p. 10). Assim, embora o organizador afirme que a antologia atende menos aos interessados na história da literatura brasileira - (...) - do que àquele leitor que vê na poesia um organismo vivo (PINTO, 2006, p.9), o trabalho, na sua forma final, assume um caráter claramente historiográfico, uma vez que tem entre seus objetivos construir um quadro que revele as marcas assumidas pela dicção poética brasileira do presente, seja aquela formulada por autores já consagrados, seja aquela proposta por poetas estreantes.

A Antologia comentada da poesia brasileira do século XXI apresenta seus capítulos organizados por ordem alfabética, segundo o sobrenome dos autores. Além disso, o número de textos selecionados varia de autor para autor, uma vez que observada a necessidade de fornecer uma amostragem representativa da produção de cada poeta. Entre os critérios adotados na organização da obra, encontram-se também o privilégio concedido à produção recente dos poetas e a inclusão de poemas ainda inéditos cedidos pelos autores. Em nota de rodapé, o organizador justifica as ausências de Hilda Hilst e Bruno Tolentino; a primeira, por não haver produzido poesia no século XXI; o segundo, por não ter autorizado a publicação de seus poemas.

Cada capítulo abre-se com o nome do autor, acompanhado de seu local e data de nascimento. Após, vem a seleção de poemas, que é acompanhada de uma leitura crítica que leva em consideração não apenas os temas abordados, mas também os recursos de natureza estética utilizados pelo poeta. Nesse exercício crítico, Manuel da Costa Pinto estabelece, na maior parte dos casos, uma relação entre os elementos detectados nos poemas selecionados e o conjunto da produção poética de cada autor.

Ao mapear, nos termos antes referidos, a produção poética brasileira do século XXI, Marcos da Costa Pinto promove a divulgação de um número significativo de poetas, cujas obras permanecem desconhecidas da maioria dos leitores brasileiros, mesmo daqueles que se dedicam ao exercício da crítica e à escrita da história da literatura brasileira. Sua antologia, a exemplo da anterior aqui examinada, abandona a pretensão totalizadora própria das histórias da literatura de feitio tradicional e amplia os caminhos a serem trilhados por uma historiografia brasileira do presente que se pretenda em consonância com as perspectivas abertas pela ciência histórica e pela Teoria da História da Literatura, em suas propostas contemporâneas.

Esse mesmo caminho é trilhado por Luís Bueno em Uma história do romance de 30, uma vez que, por suas escolhas singulares, contribui para a renovação do discurso historiográfico e, significativamente, para o redimensionamento do cânone literário brasileiro. Nesse sentido, como já foi observado, afirmam-se igualmente formas alternativas de escrita historiográfica, como aquelas situadas no campo da ego-história, ou mesmo no âmbito de uma história dos afetos (OLINTO, 2008), como é o caso de boa parte das obras que integram a coleção "Como e por que ler...", divulgadas através de editora Objetiva. Há que registrar, ainda, as experiências que sinalizam para o surgimento de uma nova consciência por parte dos historiadores da literatura, que assumem explicitamente a subjetividade e a consequente parcialidade de seus relatos.

Por fim, mas não menos importante, cabe registrar que não há aqui nenhuma intenção no sentido de desqualificar as histórias da literatura brasileira de perfil tradicional, pois foram elas responsáveis pelo inestimável trabalho de resgate de nosso passado literário, constituindo-se, ainda hoje, em importantes e incontornáveis fontes de pesquisa para aqueles que se dedicam ao estudo da literatura brasileira. $\mathrm{O}$ intuito do presente ensaio foi tão somente assinalar a emergência de novas formas no historiar a literatura, surgidas a partir de pressupostos estabelecidos, na contemporaneidade, pela Teoria da História da Literatura.

\section{Referências}

ALMERÍA, Beltrán Luis; ESCRIG, José Antonio (Org.). Teorias de la historia literaria. Madrid: ARCO/LIBROS, 2005.

BARRENTO, João. História literária: problemas e perspectivas. Lisboa: Apáginastantas, 1986.

BAUMGARTEN, Carlos Alexandre. História da literatura: origens e perspectivas atuais. Cadernos Literários, Rio Grande, v. 14, n. 2, dez. 2007.

BAUMGARTEN, Carlos Alexandre (Org.). História da literatura: itinerários e perspectivas. Rio Grande: Editora da Universidade Federal do Rio Grande, 2011.

BERND, Zilá (Org.). Antologia da poesia afro-brasileira. 150 anos de consciência negra no Brasil. Belo Horizonte: Mazza Edições, 2011. 
BUENO, Luís. Uma história do romance de 30. São Paulo: Edusp; Campinas:Unicamp, 2006.

LAJOLO, Marisa. Como e por que ler o romance brasileiro. Rio de Janeiro: Objetiva, 2004.

MALARD, Letícia et alii. História da literatura. Ensaios. Campinas: Editora da UNICAMP, 1994.

MARSHALL, Brown (Ed.). The uses of Literary History. London: Duke University Press, 1995.

MOREIRA, Maria Eunice (Org.). Histórias da literatura: teorias, temas e autores. Porto Alegre: Mercado Aberto, 2003.

MOREIRA, Maria Eunice (Org.). Histórias da literatura: teorias e perspectivas. Porto Alegre: Edipucrs, 2010.

OLINTO, Heidrun Krieger (Org.). Histórias de literatura. As novas teorias alemãs. São Paulo: Ática, 1996.

OLINTO, Heidrun Krieger (Org.). Ciência da literatura empírica: uma alternativa. Rio de Janeiro: Tempo Brasileiro, 1989.

OLINTO, Heidrun Krieger. Uma historiografia literária afetiva. Cadernos de pesquisa em literatura. Porto Alegre, v. 14, n. 1, jun. 2008.
PERKINS, David. História da literatura e narração. Cadernos do Centro de Pesquisas Literárias da PUCRS, Porto Alegre, v. 3, n. 1, mar. 1999. Série Traduções.

PINTO, Manuel da Costa (Org.). Antologia comentada da poesia brasileira do século XXI. São Paulo: Publifolha, 2006.

RUSCH, Gebhard. Teoria da história, historiografia e diacronologia. In: OLINTO, Heidrun Krieger (Org.). Histórias de literatura. As novas teorias alemãs. São Paulo: Ática, 1996.

SOUZA, Roberto Acízelo de. Introdução à historiografia literária brasileira. Rio de Janeiro: Eduerj, 2007.

SOUZA, Roberto Acízelo de. História da literatura. In: Formação da teoria da literatura. Inventário de pendências e protocolo de intenções. Rio de Janeiro: Ao Livro Técnico; Niterói: Universidade Federal Fluminense, 1987. p. 62-85.

Recebido: 10 de novembro de 2013 Aprovado: 20 de janeiro de 2014 Contato: baumg@mikrus.com.br 